\title{
GATA-2 a-t-il un rôle dans la quiescence des cellules souches?
}

Les facteurs de transcription de la famille GATA ont en commun de se fixer, par l'intermédiaire de deux doigts de zinc, à la même séquence consensus (T/A)GATA $(\mathrm{A} / \mathrm{G})$ de l'ADN (m/s 1994, $n^{\circ} 11$, p. 1174; 1995, $\left.n^{\circ} 11, p .1608\right)$. L'expression de chacune de ces protéines est fonction, non seulement du tissu (ou de la cellule) concerné, mais aussi de son stade de développement. Trois des six facteurs GATA identifiés actuellement interviennent au cours de l'hématopoïèse. GATA-1 s'exprime majoritairement au cours des différenciations érythroïde et mégacaryocytaire $(\mathrm{m} / \mathrm{s}$ 1991, $n^{\circ} 4$, p. 385), GATA-3 au cours de l'hématopoïèse foetale et du développement lymphoïde T. GATA-2 est indispensable à la fonction des cellules souches hématopoiétiques [1] et l'invalidation du gène est létale in utero. Au cours de la différenciation hématopoiétique, l'expression de GATA-2 décroît alors que celle de GATA-1 augmente. Cette évolution contraire est importante pour une différenciation hématopoiétique harmonieuse [2]. La persistance d'un taux élevé de GATA-2 est délètère pour la différenciation érythroïde, du moins chez le poulet [3]. Le groupe de A. Nienhuis confirme dans Blood [4] que la surexpression non réglable de GATA-2 dans des cellules souches murines bloque non seulement leur différenciation, mais aussi leur amplification. Les cellules médullaires ont été infectées avec un vecteur rétroviral bicistronique [MSCV-GATA-2-iresGFP (green fluorescent protein)] ce qui permet l'identification des cellules transduites par leur expression de GFP (l'expression de GATA-2 est considérée comme certaine dans les cellules $\left.\mathrm{GFP}^{+}\right)$. La fonction des progéniteurs hématopoiétiques transduits a été analysée dans différents essais biologiques in vitro et in vivo. Les progé- niteurs médullaires infectés avec le vecteur GATA-2-ires-GFP et sélectionnés sur leur émission de fluorescence forment très peu de colonies in vitro et très peu de colonies spléniques in vivo après leur injection chez un receveur murin irradié. Au contraire, la fonction des progéniteurs infectés avec le vecteur contrôle GFP est normale. Surtout, l'activité de reconstitution hématopoiétique à long terme des cellules médullaires infectées est profondément altérée par l'expression constitutive de forts taux de la protéine GATA-2. Ainsi, après greffe de cellules transduites par le vecteur GATA-2-ires-GFP, on ne détecte que des cellules exprimant pas (ou peu) de GFP (et donc de GATA-2), contrairement aux animaux greffés avec des cellules transduites par le vecteur GFP seul. Une étude attentive exclut une toxicité, une modification non spécifique du cycle cellulaire, ou une apoptose induites par l'infection. Argument supplémentaire, un même nombre de cellules immatures $\mathrm{Sca}^{+} \mathrm{Lin}^{-}$(fraction enrichie en cellules souches) est détecté immédiatement après transduction de cellules médullaires par le vecteur contrôle GFP et par le vecteur GATA-2-iresGFP, excluant un biais au niveau de l'infection des cellules immatures par le virus codant pour GATA-2. Dans les cellules infectées par ce dernier vecteur, les ARN codant pour la protéine GATA-2 virale et la protéine endogène sont détectés, et cependant, les cellules $\mathrm{GFP}^{+}$(et donc GATA- $2^{+}$) ne contribuent pas à l'hématopoïèse. Cela suggère que la quantité de GATA-2 d'origine virale est le paramètre crucial, et que si celle-ci est maintenue élevée, alors que l'expression du gène endogène décroît, la cellule ne peut pas poursuivre normalement sa différenciation. Cela explique que 12 semaines après transplantation de cellules de moelle infectées par le vecteur GATA-2-ires-GFP, l'hématopoïèse du receveur soit assurée par des cellules non infectées, ou exprimant peu le transgène, alors que $40 \%$ des cellules des receveurs greffés avec la moelle infectée par le vecteur contrôle sont $\mathrm{GFP}^{+}$. Non seulement les cellules primitives GATA-2 ${ }^{+}$sont incapables de se différencier, mais elles sont également incapables d'expansion, comme en témoigne l'altération du nombre total de cellules $\mathrm{Sca}^{+} \mathrm{Lin}^{-}$ détectées à 10 semaines après transplantation. L'ensemble de ces données pourrait suggérer que GATA-2 intervient dans le maintien des cellules souches dans un état de quiescence, assurant ainsi une réserve suffisante de cellules souches. Sa régulation négative serait requise pour que les étapes de prolifération et de différenciation prennent place. Quels signaux d'environnement (cytokines ou molécules d'adhérence) amorcent la régulation négative nécessaire à la réalisation du processus d'hématopoï̀se ? Quels gènes cibles de GATA-2 sont en cause ? Peut-être approche t-on d'un peu plus près une des clés de la détermination hématopoiétique?

D.L.

1. Tsai FY, Orkin SH. Transcription factor GATA2 is required for proliferation/survival of early hematopoietic cells and mast cell formation but not for erythroid and myeloid terminal differentiation. Blood 1997; 89: 3636-43.

2. Cunningham JM, Jane SM. Hemoglobin switching and fetal hemoglobin reactivation. Semin Hematol 1996; 33: 9-23.

3. Briegel K, Lim KC, Plank C, Beug H, Engel JD, Zenke M. Ectopic expression of a conditional GATA-2/estrogen receptor chimera arrests erythroid differentiation in a hormone-dependent manner. Genes Dev 1993; 7 : 1097-109.

4. Persons DE, Allay JA, Allay ER, et al. Enforced expression of the GATA-2 transcription factor blocks normal hematopoiesis. Blood 1999; 93 : 488-99.
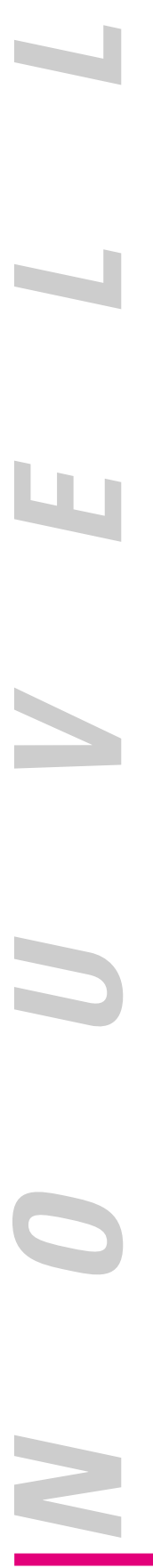